Fecha de recepción

Fecha de evaluación:

Fecha de aprobación:
02 de octubre de 2018

19 de abril de 2019

9 de diciembre de 2019

\section{Betty Silvia eAlca Gómez*}

* El presente artículo tiene origen en el desarrollo de la Tesis de pregrado en Derecho titulada al igual que el presente artículo, la cual se encuentra disponible en el repositorio de la Universidad Nacional de San Agustín de Arequipa: http://repositorio.unsa.edu.pe/handle/UNSA/6251. Tanto la tesis como el artículo son resultados obtenidos gracias al Financiamiento de los "Fondos Concursables" de CIENCIACTIVA-UNSA, y en consecuencia se otorga un especial agradecimiento a la Universidad Nacional de San Agustín de Arequipa de conformidad con el contrato N¹24-2016-UnSA. Arequipa, (Perú).

Adicionalmente parte de la información que alimenta los resultados del presente artículo implicó la aplicación de encuestas en las cuales se garantizó a las personas consultadas el tratamiento de datos, de conformidad con la Ley $N^{\circ} 29733$, ley de Protección de datos de la legislación peruana, y la autorización para la utilización de las mismas. Anexo1. Modelo de encuesta aplicada.

** Abogada por la Universidad Nacional de San Agustín de Arequipa. Becaria de "Fondos Concursables CIENCIACTIVA-UNSA", ORCID: https:// orcid.org/0000-0002-8143-8543. Correo electrónico de contacto: b.alcagomez@gmail.com. Arequipa.(Perú).

\title{
Incumplimiento de
}

las sentencias por responsabilidad civil derivado del daño médico que ordenan al Estado peruano un pago indemnizatorio*

Para citar este artículo

Alca, B. (2020). Incumplimiento de las sentencias por Responsabilidad Civil derivado del daño médico que ordenan al Estado peruano un pago indemnizatorio. Vía luris, (28), 27-51.
DOI: https://doi.org/10.37511/viaiuris.n28a2

Esta obra se publica bajo una Licencia Creative Commons AtribuciónCompartirlgual 4.0 Internacional. 


\section{Incumplimiento de las}

sentencias por responsabilidad

civil derivado del daño médico

que ordenan al Estado peruano

un pago indemnizatorio

\section{Betty Silvia Alca Gómez}

\section{RESUMEN}

El presente artículo analiza el problema del sistema indemnizatorio sanitario público en el Perú, el problema trata aquellos casos en los cuales un paciente ha sufrido un daño médico por parte del profesional de la salud en estructuras sanitarias públicas, éste se somete a un proceso judicial resultando vencedor y cuando pretende ejecutar su sentencia judicial en la práctica se denota lo complicado que resulta ejecutar dichos mandatos judiciales porque en la legislación peruana vigente, los dispositivos legales han resultado contradictorios entre sí, siendo un problema de relevancia jurídica como social, cuyo principal interés es beneficiar a los pacientes afectados a quienes se les adeuda una indemnización estatal.

De tal manera se analiza las normas legales y para el presente estudio se han denominado "causas normativas" que ocasionan el incumplimiento de dichas sentencias judiciales. De lo cual se evidencia que el actual procedimiento para ejecutar las resoluciones judiciales contra el Estado y demás dispositivos legales han resultado ineficaces en la práctica.

En cuanto a la metodología empleada se utilizó el método dogmático haciendo un análisis de la normativa vigente. Asimismo, se empleó el método cuantitativo dado que se recogió datos que complementan al trabajo realizado, siendo nuestra población todos los médicos en el ejercicio de su profesión que trabajan en estructuras sanitarias públicas, extrayéndose una muestra de 40 encuestados realizada en el año 2017, dicha información fue orientada con el fin de conocer sus opiniones del problema que se plantea y por ende buscar alternativas de solución, el trabajo de campo se detallará más adelante.

\section{Palabras clave}




\title{
Non-Compliance of the
} sentences for civil liability derived from the medical damage that the individual payment is ordered to the peruvian State

\section{Betty Silvia ellca Gómez}

\begin{abstract}
This article analyzes the problem of the public health compensation system in Peru, the problem deals with those cases in which a patient has suffered medical damage by the health professional in public health structures, he undergoes a judicial process resulting in winner and when he intends to execute his judicial sentence in practice, it is denoted how complicated it is to execute said judicial orders because in current Peruvian legislation, the legal provisions have been contradictory to each other, being a problem of legal and social relevance, whose main interest is benefit affected patients who are owed state compensation.

In this way, the legal norms are analyzed and for the present study they have been called "normative causes" that cause the non-compliance of said judicial sentences. From which it is evident that the current procedure to execute the judicial resolutions against the State and other legal devices have been ineffective in practice.

Regarding the methodology used, the dogmatic method was used, making an analysis of the current regulations. Likewise, the quantitative method was used since data was collected that complements the work carried out, being our population all the doctors in the exercise of their profession who work in public health structures, extracting a sample of 40 respondents carried out in 2017, said Information was oriented in order to know their opinions of the problem that arises and therefore seek alternative solutions, the fieldwork will be detailed later.
\end{abstract}

\section{Keywords}

Non-compliance, State, Medical Damage, Judicial sentences. Inembargability of public goods, 


\title{
Violação das sentenças de responsabilidade civil decorrentes do dano médico que determinam ao Estado peruano um pagamento de indenização
}

\section{Betty Silvia Alca Gómez}

\begin{abstract}
RESUMO
Este artigo analisa o problema do sistema de compensação de saúde pública no Peru, o problema lida com os casos em que um paciente sofreu danos médicos pelo profissional de saúde nas estruturas de saúde pública, ele passa por um processo judicial que resulta em vencedor e quando ele pretende executar sua sentença judicial na prática, é denotado o quão complicado é executar as referidas ordens judiciais porque, na legislação peruana atual, as disposições legais foram contraditórias entre si, sendo um problema de relevância jurídica e social, cujo principal interesse é beneficiar pacientes afetados que são devidos compensações estatais.
\end{abstract}

Dessa forma, as normas legais são analisadas e, para o presente estudo, foram denominadas "causas normativas" que causam o não cumprimento das referidas sentenças judiciais. Da qual é evidente que o atual procedimento para executar as resoluções judiciais contra o Estado e outros dispositivos legais tem sido ineficaz na prática.

Quanto à metodologia utilizada, foi utilizado o método dogmático, analisando os regulamentos vigentes. Da mesma forma, foi utilizado o método quantitativo, uma vez que foram coletados dados que complementam o trabalho realizado, sendo nossa população todos os médicos no exercício de sua profissão que atuam nas estruturas de saúde pública, extraindo uma amostra de 40 entrevistados realizados em 2017, afirmou. As informações foram orientadas a fim de conhecer suas opiniões sobre o problema que surge e, portanto, buscar soluções alternativas; o trabalho de campo será detalhado posteriormente.

\section{Palavras-chave}

Violação de sentença, Estado, Prejuízo Médico,

Inexecução de bens públicos, Não execução,

Resoluções judiciais, Indenização. 


\section{Violation des jugements de}

responsabilité civile découlant des dommages médicaux qui condamnent l'État péruvien à une indemnité

\section{Betty Silvia Alca Gómez}

\section{RÉSUMÉ}

Cet article analyse le problème du système d'indemnisation de la santé publique au Pérou, le problème traite des cas dans lesquels un patient a subi des dommages médicaux par le professionnel de la santé dans les structures de santé publique, il subit une procédure judiciaire entraînant vainqueur et lorsqu'il a l'intention d'exécuter sa condamnation judiciaire dans la pratique, il est indiqué à quel point il est compliqué d'exécuter lesdites ordonnances judiciaires parce que dans la législation péruvienne actuelle, les dispositions légales sont contradictoires, étant un problème de pertinence juridique et sociale, dont le principal intérêt est bénéficier les patients touchés à qui l'Etat doit une compensation.

De cette manière, les normes juridiques sont analysées et pour la présente étude, elles ont été appelées «causes normatives» qui entraînent le non-respect desdites décisions judiciaires. D'où il ressort que la procédure actuelle d'exécution des résolutions judiciaires contre l'État et d'autres dispositifs juridiques a été inefficace dans la pratique.

Concernant la méthodologie utilisée, la méthode dogmatique a été utilisée, faisant une analyse de la réglementation actuelle. De même, la méthode quantitative a été utilisée puisque des données ont été collectées qui complètent le travail effectué, étant notre population tous les médecins dans l'exercice de leur profession qui travaillent dans les structures de santé publique, en extrayant un échantillon de 40 répondants effectué en 2017, a déclaré L'information a été orientée afin de connaître leur avis sur le problème qui se pose et donc de chercher des solutions alternatives, le travail de terrain sera détaillé plus loin.

\section{Mots-clés}

Violation de jugements, État, Dommages médicaux,

Inapplicabilité des biens publics, Non-exécution,

Résolutions judiciaires, Compensation 



\section{INTRODUCCIÓN}

La medicina se sustenta en el principio del servicio al ser humano en función de su salud, sus objetivos son: propiciar su bienestar físico y mental, curar o por lo menos aliviar su enfermedad. Los presupuestos asignados al sector salud por los gobiernos en turno no han sido suficientes, como lo señala la Confederación Nacional de Instituciones Empresariales (CONFIEP) indicando que:

[...] las cifras del Banco Mundial, Perú registró un gasto público per cápita por debajo del promedio de América Latina, y mantuvo una menor participación del gasto en salud sobre el Producto Bruto Interno en comparación con los países de la Alianza del Pacífico (a excepción de México) y de la Organización para la Cooperación y el Desarrollo Económicos (OCDE) (Sociedad de Comercio Exterior del Perú- ComexPerú, 2019, párr.2)

Se puede inferir que la función preventiva de la responsabilidad civil debe ser reforzada con el objeto de prevenir en la medida de lo posible daños médicos que se podrían evitarse con buenos establecimientos de salud y profesional calificado, etc. Para ello el Estado debería asignar un mejor presupuesto, siendo un problema social que se debería de investigar y buscar solucionar lo que se deja abierto a futuras investigaciones, sin embargo, el presente artículo de investigación considera que en la misma línea es importante que la función compensatoria sea cabalmente oportuna, efectiva, es decir, que luego que una persona haya sufrido un menoscabo a su salud, siga todo un proceso judicial y su sentencia se declare fundada, para que luego se ejecute dicho mandato de inmediato ya que su derecho al pago de una indemnización está normado no solo por la legislación peruana sino por la de organismos internacionales como la Carta Europea de los Derechos de los Pacientes que se pronuncia en cuanto al periodo de cumplimiento de las indemnizaciones estableciendo que: "Todo individuo tiene derecho a recibir una compensación suficiente dentro de un período de tiempo razonablemente corto cuando haya sufrido un daño físico, moral o psicológico causado por un tratamiento proporcionado en un servicio de salud." (Carta Europea de los Derechos de Los pacientes, 2002, párr.39)
Siendo así que en la práctica diaria la ejecución de sentencias derivadas de daños médicos resulta complicada en nuestro actual ordenamiento cuya ejecución se torna en periodos largos e inciertos. Pues en esos términos no solamente el pacientevictima tiene que soportar el daño sufrido o una lamentable muerte, caso en el cual es su familia quien tiene que luchar por satisfacer su crédito frente al Estado peruano.

Ahora el problema que se trata en cuestión en torno al daño médico, se plantea aquellos casos en los que siguiendo las etapas del proceso civil, el paciente $y / o$ familiares en caso de muerte de la víctima, después de prolongados procesos judiciales obtiene una sentencia favorable que ordena al Estado, el pago de una indemnización por daño médico, sin embargo, cuando se pretende ejecutar dicha resolución judicial, nos encontramos con la normativa peruana, bajo la cual resulta difícil lograr que se efectivice el pago indemnizatorio.

Es importante señalar que a partir de interrogantes se llegó al objetivo principal que fue determinar las causas normativas que ocasionan el incumplimiento de las sentencias por responsabilidad civil derivado del daño médico que ordenan al Estado un pago indemnizatorio.

También cabe mencionar que los objetivos secundarios fueron: Explicar las normas que dilatan como normas que impiden el cumplimiento de las sentencias por responsabilidad civil derivado, así como establecer alternativas de solución frente a las posibles causas que ocasionan el incumplimiento de las sentencias por responsabilidad civil derivado del daño médico que ordenan al Estado un pago indemnizatorio.

La justificación de la investigación radica en un problema actual, de interés nacional, ante innumerables casos sobre negligencia médica cuyas sentencias indemnizatorias aún no se han efectivizado. El alcance social en principio beneficia a los pacientes y a los familiares directos de éste. Trascenderá positivamente a favor de los afectados al recibir el pago por concepto de indemnización de forma rápida, dentro de un plazo razonable como lo establece la Carta Europea de los Derechos de los Pacientes. Segunda Parte "Todo individuo tiene derecho a recibir una 
compensación suficiente dentro de un período de tiempo razonablemente corto. (Carta Europea de los Derechos de Los pacientes, 2002, párr.39)

Para el desarrollo del presente estudio se desarrolla la metodología empleada de manera más profunda que la mencionada en el resumen, el método analíticodescriptivo basada en la revisión y análisis de las sentencias judiciales peruanas. La metodología de la selección de sentencias se realizó con en el método cuantitativo extrayéndose una muestra recogida del Diario Oficial el peruano, el cual contienen casaciones judiciales (El recurso de casación es un recurso extraordinario que tiene por objeto anular una sentencia judicial que contiene una incorrecta interpretación o aplicación de la Ley) y se realizó la búsqueda a través de los números de expedientes en el Sistema del Poder Judicial para obtener finalmente las sentencias provenientes de los años 2014 al 2017, realizándose la selección en base a determinadas características que los demandados sean las estructuras sanitarias del Estado peruano y /o el profesional médico, que efectivamente exista un daño médico, y que sean de los años 2014 al 2017.

Asimismo, se empleó el método cuantitativo dado que se recoge datos los cuales buscan complementar al trabajo realizado, siendo nuestra población 40 médicos en el ejercicio de su profesión que trabajan en estructuras sanitarias públicas, de tal manera que es fue necesario recoger dicha información a fin de conocer sus opiniones del problema que se plantea y por ende de buscar alternativas de solución al problema.

En cuanto a la encuesta realizada fue de carácter referencial, de carácter anónima, la participación fue voluntaria, se evidencia el consentimiento informado en el mismo documento de aplicación, con la finalidad de recoger opiniones de los galenos en aras de una posible solución al problema en cuestión. La población fue todos los profesionales médicos en ejercicio de su profesión provenientes de establecimientos de salud pública en la ciudad de Arequipa.

La muestra fue tomada en el año 2017 conformada por 40 médicos en el ejercicio de su profesión y que trabajaran en estructuras sanitarias públicas en la ciudad de Arequipa, se recogió dicha muestra a través del instrumento, siendo este un cuestionario de forma presencial.
El tratamiento Estadístico: Microsoft Excel 2010 en cuanto a los gráficos y Stata 2013 cabe mencionar que en la Gráfica 3 líneas más abajo, se realizó un análisis multivariado de las variables por ser el principal objetivo conocer cuáles son las causas que ocasionan el incumplimiento de sentencias en el daño médico, con el comando pca Stata escogió a los componentes principales y con el comando estat loadings nos mostró el número de componentes a elegir entre las variables (Presupuesto, Funcionarios Públicos, Normas, Cultural Estatal de No Pago), es decir, las causas posibles. La prueba de KaiserMeyer-Olkin (KMO) estima un valor que de acuerdo a su ubicación en una escala permitir concluir si del análisis realizado es conveniente, ya que obtuvimos un $\mathbf{0 . 5 1 7 9}$, siendo un valor que no es inferior a $\mathbf{0 . 5}$, puesto que, si este valor KMO se aleja, es más conveniente, se rechaza la hipótesis nula HO.

Por tanto, se concluye que es poco probable que la matriz de correlación sea una matriz de identidad, y por tanto la correlación entre las variables es estadísticamente significativa.

Se utilizó el método dogmático que no se remite a un análisis sesgado de normas positivas, sino también a un estudio de la doctrina, jurisprudencia.

También se consideró el método sociológico porque analiza un problema social actual, utiliza la observación de los hechos sociales, una realidad que afecta principalmente a los pacientes que recurren a establecimientos de salud pública, la mayoría de ellos son de escasos recursos, se orienta a un sólo un grupo de personas con ciertos caracteres exteriores comunes, sean de instituciones públicas como lo señala Costa (2018) la población censada afiliada a un seguro de salud, en el año 2017, los afiliados al Sistema Integral de Salud y El Seguro Social de Salud supera al privado según el Instituto Nacional de Estadística e Informática.

A fin de analizar el problema de estudio descrito con anterioridad referente al caso de todo paciente que luego de seguir las etapas del proceso civil peruano obtiene un mandato judicial favorable, existen normas vigentes peruanas que la obstaculizan generando dilación injustificada que favorece al Estado peruano, al tratarse de instituciones de salud pública, siendo responsable solidario, resulta muy difícil efectivizar dichas sentencias judiciales, para ello resulta necesario revisar conceptos básicos y la normativa que las regula. 
A continuación se abordarán en términos generales conceptos como: responsabilidad profesional médica, siendo la obligación que tienen los médicos de reparar y satisfacer las consecuencias de los actos, omisiones y errores voluntarios e involuntarios, incluso dentro de ciertos límites, cometidos en el ejercicio de su profesión.

Los elementos constitutivos de la responsabilidad civil médica en el Perú en torno al daño médico son:

\section{La ilicitud o antijurícidad}

La ilicitud se refiere cuando se realiza todo acto contrario a las normas jurídicas. Según Maylle (2012) ha establecido que "Cuando el acto médico escapa de la norma o de la relación contractual se produce la antijurícidad" (p.250)

En el caso de los profesionales de salud son responsables de cualquier error u omisión establecida en la Ley General de Salud como norma específica y normas generales.

\section{El factor de atribución}

Los factores de atribución en la responsabilidad civil son objetivos (dolo) y subjetivo (culpa). En el caso de la responsabilidad por daños médicos el factor de atribución más utilizado es el subjetivo.

\section{Nexo causal}

En palabras de Calabresi citado por Espinoza (2014) afirma que la existencia de causalidad se produce entre una actividad y el daño en sí, toda conducta consecuente, repetitiva de dicho acto incrementará las posibilidades de que el daño se realice, en ese orden de ideas, la responsabilidad médica sólo puede verificarse cuando existe culpa o negligencia por parte del profesional de la salud, pero la propia negligencia no es suficiente para establecer la responsabilidad al mismo, ya que se necesita la existencia de un nexo de causalidad entre la conducta negligente del profesional y el daño por el que se reclama.

Al respecto Maylle (2012) ha señalado que:

La teoría del riesgo, el que ejerce una función, una profesión, el que labora con la responsabilidad de manipular aparatos complejos como el que conduce un vehículo, asume los riesgos que ese ejercicio implica. En el caso del médico asume el riesgo de hacer una mala operación, el riesgo de hacer un diagnóstico incorrecto, de recetar una medicación que dañe al paciente entre otros. En el derecho penal esta casualidad no es necesaria que este en forma concreta y determinada, lo único que importa al juzgador es que el hecho se haya producido y causado un daño (p.255)

De tal manera el elemento daño constituye un hecho imprescindible para que pueda surgir la responsabilidad; he ahí ante la ausencia de este elemento, la acción entablada por el paciente-victima frente al profesional de la salud carecería de causa y no habría relación de causalidad, por ejemplo, si se ha operado de manera errónea a un paciente, el acto lo ha realizado el médico y por consecuencia se ha producido un daño cometido por él mismo, se produce dicha relación.

De tal manera el nexo de causalidad, es un requisito fundamental para determinar la responsabilidad atribuida al profesional de la salud por sus actos. En otras palabras, es fundamental para determinar la relación de causalidad la actuación del personal de la salud con el consecuente daño producido.

\section{Daño}

El daño entendido como menoscabo a un bien jurídicamente tutelado, la salud, para el caso que se concierne.

Por otra parte, las etapas en el proceso civil peruano son:

a. La Etapa Postulatoria: en esta etapa, el demandante y demandado) presentan al órgano jurisdiccional sus proposiciones que van a ser materia de prueba.

b. La Etapa Probatoria: aquí, las partes prueban los hechos alegados.

c. La Etapa Decisoria: en esta etapa, el juez opta por una de las proposiciones fundamentadas y probadas durante el desarrollo del proceso. (Sentencia)

d. La Etapa Impugnatoria: en ella, la parte quien no se encuentra conforme con la decisión del 
órgano jurisdiccional, tiene el derecho de exigir un nuevo examen de la decisión emitida se considera que ésta tiene un vicio o error.

e. La Etapa Decisoria: es la etapa que permiten convertir en eficaz la "decisión definitiva" obtenida en el proceso, mediante la ejecución de la sentencia.

Es esta última etapa la que se cuestiona en el presente artículo, que aquella decisión judicial definitiva no se efectivice la ejecución debido a los obstáculos normativos que se desarrollan a posterioridad.

\section{Normas que ocasionan el incumplimiento de sentencias por responsabilidad civil derivado del daño médico}

Por consiguiente, se desarrolla en este punto el eje principal del problema en cuestión se considera a las siguientes normas como dispositivos legales que generan dilación como impedimento para que se ejecuten las sentencias judiciales por responsabilidad civil derivado del daño médico en estructuras sanitarias públicas, siendo lo siguiente:

\section{-Ejecución de obligación de dar suma de dinero por el Estado (análisis del artículo 47 de la ley 27584)}

Un tema recurrente en la ejecución de sentencias es la eficacia de las mismas. En este contexto la tutela jurisdiccional efectiva prevista en el artículo 139 inciso 3 de la Constitución Política del Perú reviste fundamental importancia por cuanto dentro de su contenido esencial se vislumbra el derecho a la ejecución de sentencias. Dicho incumplimiento tardío, parcial vulnera este derecho constitucional, así como también vulnera otros derechos constitucionales como lo ha señalado la Defensoría del Pueblo: "derecho a la igualdad y su aplicación a las partes en un proceso, el debido proceso".

El problema radica en lo actualmente normado, es decir, en lo establecido por la ley $N^{\circ} 27584$, ley que regula el procedimiento contencioso administrativo es una causa normativa que regula el procedimiento por el cual deben seguir aquellos vencedores en un proceso judicial y cuando el Estado sea el perdedor, sin embargo, diversas opiniones y en la práctica ha resultado ineficaz dicho cumplimiento.
Esta norma establece que todos los procesos judiciales en las cuales se haya declarado fundada una sentencia condenatoria, es decir, aquellas sentencias en las cuales se establece que el Estado (Administración Pública) deba de pagar sumas de dinero. En palabras de Casassa (2016) se señala que:

Nuestro proceso de ejecución de obligación de dar suma de dinero tiene un modelo hispánico medioeval y consecuentemente ha insertado en su interior a la oposición, contradicción como ahora le conocemos el mismo que puede ser invocado por el ejecutado solo en supuestos específicos (p.160).

En ese sentido lo puede realizar cualquier persona, pero tratándose de aquellas demandas contra el Estado peruano, resulta ineficaz. Ante ello resulta necesario proponer algún mecanismo de solución para asegurar el respeto del debido proceso y la tutela jurisdiccional en consecuencia la ejecución de sentencias en las cuales el Estado peruano resulta ser el demandado y sobre todo cuanto se trate de aquellas sentencias derivadas de un daño médico, ya que se afecta a las personas que se encuentran en un estado de vulnerabilidad al ser hospitalizados en establecimientos de salud públicos, al confiar y ponerse en manos del médico y demás personal de salud, su vida, integridad física, psíquica y salud, siendo derechos personalísimos de los afectados.

\section{La Ley $N^{\circ} 30137$; criterios de priorización para la atención del pago de sentencias judiciales}

La Ley $N^{\circ} 30137$, Ley que regula criterios de priorización para la atención del pago de sentencias judiciales contra el Estado, es una causa normativa, se entendía que el objeto de la norma era pagar aquellas deudas sociales, sin embargo, a nuestro parecer viene afectando gravemente a aquellas deudas provenientes de un daño médico, puesto que aquellos pagos se encuentran regulados en una penúltima escala, afectando dos derechos constitucionales, tales como el derecho a la tutela jurisdiccional efectiva y el derecho a la igualdad lo cual se manifiesta en palabras de Villa-García (2014) señala que:

Esta ley ha llegado al absurdo de establecer en su artículo segundo, numeral 2.1, que el Estado 
peruano, regiones, municipalidades, etc., cuando hayan sido derrotados en un litigio (lo que ocurre con frecuencia) y la sentencia judicial tenga la calidad de cosa juzgada, que los pagos correspondientes, es decir, pagar su deuda, va a estar sujeta de acuerdo a los siguientes criterios:

\section{[...] Cuarto, otras deudas de carácter social (EI} énfasis de las negritas fue agregado por la autora) y [...]. (p. 372)

Respecto a este cuarto considerando denominado "Otras deudas de carácter social" el reglamento de la Ley $N^{\circ} 30137$ ha regulado este criterio de la siguiente manera: "[...] b. Derivadas de negligencias médicas en centros hospitalarios públicos [...]". (El énfasis de las negritas y cursivas fue agregado por la autora).

De lo cual se evidencia una gran dilación al establecer categorías que dan prioridad al cumplimiento de unas sentencias de otras y aquellos mandatos judiciales que ordenan las indemnizaciones contra el Estado se encuentran regulados en un penúltimo lugar siendo los pacientes en establecimientos de salud pública los más afectados, se considera como injusta este tipo de prioridades, pues el daño médico implica la existencia de una afectación a la salud y a la vida de la persona que a nuestro criterio tiene la misma relevancia que otro tipo de sentencia judicial.

\section{Artículo 73 de la Constitución Política del Perú}

La Constitución Política del Perú regula la inembargabilidad de los bienes del Estado y a la fecha no existe una clasificación de bienes (muebles e inmuebles) para determinar la calidad de inembargables siendo una causa normativa que impide el cumplimiento de las sentencias judiciales contra el Estado.

Con respecto a la regulación de bienes del Estado, en innumerables sentencias revisadas en el ámbito de la responsabilidad civil médica tanto contractuales como extracontractuales se han interpuesto medidas cautelares de embargo, siendo que estas han devenido improcedentes muchas veces, porque la legislación vigente lo ha normado y hasta la fecha no hay una distinción clara entre bienes de dominio público y bienes de dominio privado del Estado peruano. Siendo un problema vigente hasta la actualidad.
El fundamento de la inembargabilidad, como causa normativa, se sitúa en el principio de auto tutela de la Administración y del cumplimiento de sus fines. Ledesma (2013) establece que:

La inembargabilidad de los bienes [...] busca evitar poner en riesgo el funcionamiento mismo del Estado [...] no se puede invocar cuando se trata de sentencias judiciales, con miras a garantizar la seguridad jurídica y el respeto de los derechos [...] (p. 100)

De lo expuesto se coincide con la autora el fundamento de la inembargabilidad busca evitar poner en riesgo el funcionamiento mismo del Estado. También estamos de acuerdo con que la inembargabilidad del Estado no se puede invocar cuando se trata de sentencias judiciales las cuales deben cumplirse puesto que el Estado es sujeto de derecho privado y debe cumplir sus obligaciones como cualquier persona y cabria la necesidad que la legislación peruana regule esos vacíos normativos fijando que bienes de dominio público son susceptibles de ser embargables sin generar desmedro o riesgo el funcionamiento del mismo Estado peruano como posible solución al problema planteado.

Finalmente, nuestra legislación regula normativa que ocasiona tanto la dilación como el impedimento para ejecutar mandatos judiciales derivados de un daño médico en estructuras sanitarias del sector público, así como la falta de implementación de mecanismos legales que permitan su cumplimiento cuando se ordena al Estado peruano, el pago de sumas dinerarias por concepto de indemnización. Se debe de fortalecer la prevención en el sector de salud, así como la compensación en términos económicos, a consecuencia del daño sufrido ya que en muchos países se ha legislado de tal manera que el sistema de indemnizaciones a favor de pacientes se encuentra fuertemente reforzado a través de la legislación comparada a raíz de este importante problema legal como social.

\section{El Estado y los Servicios Públicos}

El Tribunal Constitucional peruano (1997) considera que el Estado tiene:

[...] una doble personalidad jurídica, cuando ejerce el ius imperium, actúa como persona de derecho público y cuando contrata o administra sus bienes patrimoniales privados actúa como 
persona de derecho privado [...] no puede el Estado tener un nivel de preeminencia [...]. (Exp. № 006-96-I/TC, fundamento 5).

Se desprende del citado apartado que el Estado tiene una doble personalidad que en algunos casos es de derecho público, es decir, tiene la organización administrativa y la representación del país, en estos casos su potestad es de manifestación del ius imperium o del poder del Estado. En esta faceta del Estado se consideran características peculiares que García (2014) describe de la siguiente manera: "[...] está dotada de las siguientes características: unidad (un solo cuerpo político-unificador), impersonalidad (voluntad reside en el propio Estado), identidad (el Estado actúa por sí mismo), permanencia (prolongado en el tiempo)" (p.200), esta personalidad del Estado es diferente cuando actúa con personalidad de derecho privado, pues en estos casos puede contratar como cualquier otra entidad particular, en este tipo de personalidad del Estado se encuentra al mismo nivel que las demás personas que interactúan de forma económica, comercial, laboral, etc., este criterio se evidencia en el artículo 59 del Código Procesal Civil que establece lo siguiente:

Cuando el Estado y sus dependencias, o las empresas públicas y privadas con participación económica determinante de aquél intervienen en un proceso civil, cualquiera sea la calificación o ubicación procesal que se les asigne, se someterán al Poder Judicial sin más privilegios que los expresamente señalados en este Código. (Código Procesal Civil, 1993)

Esta doble dimensión que corresponde al Estado moderno y democrático lamentablemente no ha sido comprendida adecuadamente por las instituciones como el Congreso de la República, el Tribunal Constitucional o el Poder Judicial, esto debido a la complejidad de distinguir una dimensión de la otra y debido a la moderna concepción del Estado como sujeto de derecho privado.

Cuando hablamos del Estado, la persona jurídica puede desdoblarse en una entidad que representa a la ciudadanía en su conjunto, actúa como parte del derecho político como la instancia que da soporte a una comunidad. Finalmente, el Estado somos todos y también son aquellas instituciones que lo componen y que le dan fortaleza para que puedan existir los contornos que forman parte de lo que en doctrina se denomina la teoría del Estado.
El Estado cuando actúa dentro de un proceso judicial tiene las mismas atribuciones que cualquier ciudadano y de lo contrario podría fomentarse una impunidad desde el propio Estado para el cumplimiento de obligaciones judiciales. Respecto a los servicios públicos el artículo primero de nuestra actual Constitución Política señala que: "La defensa de la persona humana y el respeto de su dignidad son el fin supremo de la sociedad y del Estado" (Constitución Política del Perú, 1993, art.1).

Lo cual se logra en parte mediante una adecuada creación y prestación ininterrumpida de los servicios públicos. A partir de allí; se desprende que los "servicios públicos" son las actividades asumidas por órganos o entidades públicas o privadas, creados por la Constitución o las leyes, para dar satisfacción en forma regular y continua a cierta categoría de necesidades que son de interés general, bien sea en forma directa, mediante concesionario o a través de cualquier otro medio legal, con sujeción a un régimen de derecho público o privado según corresponda.

La creación de los servicios públicos procede por disposiciones establecidas por la Constitución Política de nuestro país o por previsiones de ley, el crear un servicio público significa que el Estado ha decidido suministrar prestaciones directa o indirectamente a la colectividad, bien sea que el Estado asuma la administración, la gerencia o el manejo de una actividad para satisfacer de manera regular y continua cierta categoría de necesidades de interés colectivo teniendo la iniciativa y el control sobre esta prestación a cargo de las particulares. La Administración Pública se desarrolla a través de la prestación de servicios públicos con el fin de satisfacer la atención sanitaria en nuestro país y conforme a las normas vigentes el Estado debe regularla, vigilarla y promoverla en aras de lograr la reducción de mala praxis y la Ley General de Salud en su Título Preliminar Iv Considerando regula lo siguiente: "La salud pública es responsabilidad primaria del Estado". Consideramos que esa responsabilidad abarca desde la prestación de un buen servicio público hasta en los casos en los cuales se hubiese ocasionado un daño médico que se efectivice su cumplimiento de la reparación del daño causado.

\section{La Responsabilidad Civil Médica y Responsabilidad del Estado en estructuras sanitarias}

La doctrina y la ley ha clasificado la responsabilidad civil en contractual y extracontractual, en virtud 
del origen de la obligación de reparar: bien por la violación de las convenciones pactadas en un contrato, bien por violación general del principio de no causar daño a terceros.

En el ordenamiento jurídico español la responsabilidad se encuentra regulada en el artículo 1902 del Código Civil Español que establece: "El que por acción u omisión causa daño a otro, interviniendo culpa o negligencia está obligado a reparar el daño causado." Como complemento el artículo 1903 del Código Civil Español lo siguiente: "La obligación que impone el artículo anterior es exigible, no sólo por los actos u omisiones propios, sino por los de aquellas personas de quienes se debe responder." (Real Decreto, 1889). Asimismo, el Código Civil peruano en el artículo 1325 señala que:" El deudor que para ejecutar la obligación se vale de terceros, responde de los hechos dolosos o culposos de éstos, salvo pacto en contrario" (Código Civil peruano, 1984).

En los artículos antes citados nos indica que no solo somos responsables de lo que hacemos, sino que también somos responsables de aquellos que dependan de nosotros.

Ahora se desarrolla en forma breve los elementos de la responsabilidad civil como primer elemento tenemos a la ilicitud en palabras de Carhuatocto (2010) la define como una violación o prohibición establecido por el ordenamiento jurídico, las buenas costumbres, las normas de orden público, etc. en casos de responsabilidad contractual como extracontractual, tal es el caso expuesto de negligencia ortodrómica que causa reabsorción ósea.

Como presupuesto de la responsabilidad civil se puede observar en el artículo 1321 del Código Civil: "Queda sujeto a la indemnización de daños y perjuicios quien no ejecuta sus obligaciones por dolo, culpa inexcusable o culpa leve", el mencionado artículo regula la responsabilidad civil contractual y el artículo 1969 del Código Civil.: "Aquel que por dolo o culpa causa un daño a otro está obligado a indemnizarlo. El descargo por falta de dolo o culpa corresponde a su autor" y el artículo 1970 C.C.: "Aquel que, mediante un bien riesgoso o peligroso, o por el ejercicio de una actividad riesgosa o peligrosa, causa un daño a otro, está obligado a repararlo."

Estos últimos artículos se refieren a la configuración de una responsabilidad civil extracontractual, y el afectado tiene el derecho de opción o demandar vía contractual o extracontractual dependiendo cual le sea más conveniente analizando el caso en concreto.

El segundo elemento es la antijuridicidad al respecto podemos mencionar un caso sonado peruano fue en el año del 2010, la amputación por error de la pierna sana del de un paciente en el Hospital Alberto Sabogal del Callao, perteneciente al Seguro Social de Salud (EsSalud) evidencia como el acto del médico al ocasionar el daño al señor contraviene la norma lesionando el bien jurídico tutelado, la salud.

El tercer elemento el factor de atribución, la responsabilidad civil son objetivos (dolo) y subjetivo (culpa). En el caso de la responsabilidad por daños médicos el factor de atribución más utilizado es el subjetivo, mientras que el dolo, esto es la intención de causar un daño médico es seguido en el proceso penal, empero si no se constituye como parte civil en el proceso penal, el afectado o la familia puede reclamar la indemnización por daños en un proceso civil independiente.

El cuarto elemento el nexo causal, se puede mencionar el caso peruano de un demandante que sufrió un accidente automovilístico resultando con fracturas en la tibia, peroné y fémur. A consecuencia de ello, fue trasladado al hospital del Seguro Social de Salud, en donde fue sometido a una intervención quirúrgica a cargo de los médicos traumatólogos Señala que después de quince días, fue dado de alta, pero que con el transcurrir del tiempo no notaba ninguna mejoría, ya que no podía caminar y sufría de fuertes dolores; por lo que contrató los servicios profesionales del médico, quien después de la revisión y diagnóstico del paciente, es que dispuso que se enyese la pierna del recurrente para otorgarle estabilidad y evitar rotaciones. Indicó que dicha situación no le permitió levantarse de la cama por tres meses, lo que produjo que le aparecieran escaras. Es por ello que consideró que la operación no fue realizada correctamente, ya que tuvo la necesidad de acudir a otro médico para que le otorgue un nuevo tratamiento que le permita su recuperación. Expediente $\mathrm{N}^{\circ}$ 01664-2007-0-0401-JR-Cl-07 (2006)

En este caso hay que tener en cuenta que la propia negligencia no es suficiente para demostrar la culpabilidad del demandado, ya que requiere la existencia de un nexo de causalidad entre la conducta negligente del médico y el daño por el que se reclama. 
Estrella (2009) señala que:

En el ámbito jurídico el nexo de la relación causal está considerada como el elemento esencial de la responsabilidad civil; de ahí, la importancia de que la acción antijurídica no es punible si no media entre el hecho imputable y el daño, el nexo de causalidad para que el autor de ese comportamiento deba indemnizar el perjuicio. (p.88)

De lo establecido, es imprescindible dicha relación causal a fin de precisar el vínculo entre el acto y su consecuencia para valorar la cuantía del daño,

Por último, el elemento daño, según Bustamante y Flores (2004) el daño sufrido por el paciente, si es posible es un daño objetivo y como toda persona tiene al derecho a la salud y que no se vulnere protegida por el derecho, entonces debe ser lo más pronto indemnizado conforme la normativa vigente.

En el Perú, la responsabilidad médica está regulada en general por la responsabilidad de los profesionales el artículo 1762 del Código Civil que indica: "Si la prestación de servicios implica la solución de asuntos profesionales o de problemas técnicos de especial dificultad, el prestador de servicios no responde por los daños y perjuicios, sino en caso de dolo o culpa inexcusable." Para un sector de la doctrina, el médico va responder por incumplimiento contractual según las reglas de la culpa profesional, siendo su retribución económica pagada por el ente de salud al que pertenece siendo el eje del problema de investigación el sector de salud público, sin embargo, otro sector de la doctrina señala que no hay responsabilidad contractual con el paciente y el profesional de salud debe responder por "deber genérico de no causar daño a nadie".

Se observa que en la práctica el demandante (paciente) puede optar por demandar sea por incumplimiento contractual o responsabilidad extracontractual, teniendo el derecho de opción de regímenes de responsabilidad civil, se elegirá aquel que sea más beneficioso a la víctima del daño, es decir, indefinida en la medida que existe hechos que pueden encuadrar tanto en la culpa contractual como en la extracontractual por ejemplo un asegurado de Seguro Social de Salud del Perú (ESSALUD ) puede optar por demandar al establecimiento de salud ( régimen contractual) o por el deber genérico de no hacer daño a terceros (régimen extracontractual), la doctrina busca unificar estos dos regímenes en aras de beneficiar en lo mejor posible al paciente afectado.

Ahora la responsabilidad del Estado ha ido evolucionando a largo de la historia desde la aparición de la figura "Estado", han existido teorías que señalaban que el Estado es independiente del servidor público y por tanto no responde por los daños ocasionados por sus dependientes, en este caso el profesional de la salud. En la actualidad se tiene clara la idea que la responsabilidad civil del Estado es objetiva, es una responsabilidad que estará siempre dependiendo de los profesionales de salud encargados de brindar la mejor atención posible al paciente. Asimismo, Canales cita a Espinoza (2006) comentando lo siguiente:

[...] tanto la doctrina, la legislación, como la jurisprudencia comparadas, distinguen la responsabilidad del Estado, de la responsabilidad de la Administración Pública, entendida esta última como una estructura de la cual se vale el Estado para el cumplimiento de sus fines. (p. 36)

Se recoge el artículo de Sánchez (2015):

La responsabilidad patrimonial de la Administración es una responsabilidad directa [...]. De este modo, los afectados no tienen que determinar la culpabilidad de la persona física generadora de la actuación dañosa, sino que pueden exigir directamente a la Administración el pago de la correspondiente indemnización, pues el derecho siempre lo tienen frente a ella. (p.5)

Adicionalmente señala el autor que dicha responsabilidad debe ser determinada judicialmente, la necesidad de iniciar un proceso contencioso administrativo en el cual se determine la responsabilidad y la indemnización que debe asumir la Administración por la actuación u omisión desplegada.

Se entiende que el Estado al ser una persona jurídica, por tanto, puede producir daños al igual que cualquier persona y el acto ilícito es ocasionado por los profesionales de salud, quienes son sus subordinados, dicha responsabilidad no libera de responsabilidad al ente estatal.

Dicha responsabilidad parte de la desconcentración de sus servicios públicos en los diversos centros de atención médica que tiene en todo nuestro país, siendo la responsabilidad civil de la institución sanitaria (la administración), si bien es imposible 
que se garantice que estos establecimientos tengan el personal idóneo y debidamente calificados, sin embargo, subsiste una responsabilidad de la entidad con el trabajador de la salud pública cuando éste ocasione algún tipo de daño a sus pacientes, de esta manera el artículo 1325 del Código Civil peruano señala que: "El deudor que para ejecutar la obligación se vale de terceros, responde de los hechos dolosos o culposos de éstos, salvo pacto en contrario", de tal manera son las entidades de salud que a través de sus profesionales médicos contratados brindan un servicio público, la norma antes señalada le es aplicable puesto que subsiste la obligación de supervisar y controlar el desempeño laboral del indicado personal.

Se observa que en Código Civil peruano se regula la responsabilidad solidaria de la persona natural o jurídica por el daño de su dependiente laboral, de esta manera el artículo 1981 del Código Civil establece que:

Aquel que tenga a otro bajo sus órdenes responde por el daño causado por ésta último, si ese daño se realizó en ejercicio del cargo o en cumplimento del servicio. El autor directo y el autor indirecto están sujetos a responsabilidad solidaria.

Si bien el artículo antes citado establece la responsabilidad solidaria en todos los casos, tanto el establecimiento de salud o servicio médico de apoyo es solidariamente responsable por los daños y perjuicios que se ocasionan al paciente, este criterio es muy difundido en nuestra cultura jurídica estaría cambiando las bases para su concepción, esto se puede advertir en la novísima introducción de la institución del "compliance corporate" cuya traducción es la conformidad de la empresa, institución relacionada a las buenas prácticas de la organización empresarial donde la entidad no responde por los daños que ocasionen sus subordinados cuando esta ha realizado las acciones necesarias para evitarlo. En nuestro país esta institución ingresa en el año 2015, pero específicamente para el caso de los delitos de cohecho activo trasnacional, pero que su aplicación en el derecho comparado y la seguridad que tiene para una sociedad de economía de mercado con predominio capitalista podría que en el futuro se haga extensivo a otros tipos de responsabilidades.

En nuestra actual legislación la responsabilidad de la entidad por el daño médico será aplicable en todos los casos conforme a las normas antes indicadas, pues además se tiene en forma clara y especifica se tiene a la Ley General de Salud, como norma especial en el artículo 48 que establece:

El establecimiento de salud o servicio médico de apoyo es solidariamente responsable por los daños y perjuicios que se ocasionan al paciente, derivados del ejercicio negligente, imprudente o imperito de las actividades de los profesionales, técnicos o auxiliares que se desempeñan en éste con relación de dependencia [...] (Ley General de Salud, 2001, art 48).

En ese sentido Maylle (2012) señala que: “Si el juez ha determinado una responsabilidad civil o reparación civil solidaria como persona jurídica del cual es dependiente el profesional de salud, estando ambos, es decir empleado y empleador obligados solidariamente a la restitución o resarcimiento pecuniario" [...] (p.260), esto significa que además del profesional de salud quien responde penal y civilmente son las instituciones de salud quienes responderán civilmente respecto a los montos indemnizatorios.

En el ámbito penal, el artículo 95 del Código Penal peruano señala que: "La reparación civil es solidaria entre los responsables del hecho punible y los terceros civilmente obligados", asimismo el artículo 99 establece que: "Procede la acción civil contra los terceros cuando la sentencia dictada en la jurisdicción penal no alcanza a éstos".

Estos artículos evidencian la responsabilidad solidaria de terceros, responsables del daño ocasionado; de esa manera la solidaridad se refiere a los partícipes directos y extensivamente a los terceros, es así que la jurisdicción civil, como la penal, sea indemnización o reparación civil son obligados distintas personas del condenado y cuando éste se encuentre en relación de dependencia. La solidaridad en la reparación civil no impide la posibilidad que el pagador de ella (existiendo otros participes en el delito) puede iniciar acción contra los demás responsables por derecho de repetición.

En palabras de Leysser (2017):

[...] la regla de solidaridad [...] pretende concentrarlo todo en la reparación de las víctimas [...] la salud e integridad física en el ámbito sanitario, la relevancia de la función preventiva, a la cual 
se reconoce una jerarquía no menor a la de la función compensatoria. (p.865)

Conforme al presente análisis queda claramente demostrada la responsabilidad solidaria de la entidad pública y a su vez del Estado por el daño médico ocasionado por sus dependientes, sin embargo, no en todos los casos existe responsabilidad solidaria porque hay situaciones en las cuales el Estado es el único responsable como en el caso de las enfermedades intrahospitalarias entre otras circunstancias. Pero el problema planteado pone en relevancia la necesidad justa del cumplimiento sentencias judiciales derivadas de daños médicos en establecimientos de salud públicas.

\section{La Efectividad y Ejecución de Sentencias en el Perú}

Uno de los autores que consideramos en la investigación ha sido Pérez (2014) señala que: “De nada serviría obtener una sentencia favorable si después no existieran los medios para su adecuado y fiel cumplimiento". (p.136)

Ante esta problemática el Tribunal Constitucional ha sugerido una serie de recomendaciones que podrían implementarse para el cumplimiento de las sentencias, cabe destacar la sentencia 02598-2010PA/TC, Perú, 11 de junio de 2013, fundamento 16, en cuanto a la ejecución de mandatos judiciales el Colegiado recomienda a) iniciativas legislativas por parte del Poder Ejecutivo; b)reglamentos en el sentido que el Poder Ejecutivo deberá reglamentar mecanismos previsibles y claros para efectos de que los funcionarios de la Administración reconozcan sus competencias y atribuciones en la ejecución de sentencias; c) información que parte también del Poder Ejecutivo en lo que concierne base de datos actualizadas sobre las sentencias que exigen determinadas actuaciones de los poderes públicos ;d) Procedimientos y previsión presupuestaria, todas estas recomendaciones con el objeto de garantizar una tutela jurisdiccional efectiva.

Es importante también mencionar que en la sentencia emitida del Tribunal Constitucional peruano expresó lo siguiente: "[...] corresponde al Presidente de la República cumplir y hacer cumplir las sentencias y resoluciones de los órganos jurisdiccionales." (Luis Alberto Lalupu Sernaqué c. resolución judicial, fundamento 12). De tal manera, es la obligación del propio Presidente de la República resguardar el cumplimiento de las sentencias dictadas por el Poder Ejecutivo.

De tal forma Pérez (2014) señala que:

[...] La ejecución de una sentencia debería también tener un plazo razonable para su ejecución, de lo contrario mostrará que el sistema es ineficiente. Es inconcebible [...] que el cumplimiento de una resolución judicial final pueda demorar más que el propio proceso donde se declaró el derecho. (p.131)

Este comentario por parte del autor se evidencia en la sentencia emitida por el Tribunal Constitucional (Colegio de Abogados de Ica, Defensoría del Pueblo (Acumulados) que señaló lo siguiente: “[...] establecer un plazo máximo de 5 años para que el Estado cubra proporcionalmente la totalidad de una obligación [...] no es razonable ni constitucional el incumplimiento de sentencias judiciales que, teniendo ya más de 5 años de dictadas [...]". (Colegio de Abogados de Ica, Defensoría del Pueblo (Acumulados) c. resolución judicial, fundamento 55, 2004, párr.142)

La sentencia ordena al Estado que el cumplimiento de una sentencia se ejecute en un plazo máximo de 5 años, ordenando a Ministerio Público investigar los motivos que se hayan estado incumpliendo los pagos por mandato judicial, lamentablemente las disposiciones normativas como la presente redundan en una protección a los funcionarios encargados del presupuesto para evitar el cumplimiento de la deuda social limitando a la existencia de recursos económicos en el pliego presupuestario. Así Priori (2007) comenta lo siguiente:

Suelen presentarse algunos problemas cuando la parte que debe cumplir lo dispuesto por una sentencia es el Estado o una entidad estatal, pues a menudo incurren en la inejecución del mandato judicial. Esta situación se ha visto favorecida por la persistencia de ciertas reglas y principios (plasmados en normas) que conceden una situación privilegiada a la administración y entidades públicas, distinta a la que corresponden a las personas particulares o entes privados para efectos de la ejecución de las sentencias. (p.288)

Del comentario del autor se infiere que los obstáculos para la ejecución de las sentencias están identificados por la doctrina nacional como: el principio de legalidad presupuestaria y la inembargabilidad de 
los bienes del Estado, es decir, el primero en marco a la Ley General del Presupuesto y los principios presupuestarios y el segundo principio que trataremos en líneas posteriores.

Para el cumplimiento de sentencias judiciales la norma prevé modificaciones presupuestarias al respecto Pisconte (2015) indica "[...] modificación presupuestaria a) Realizar una evaluación [...] y b) Priorización de metas presupuestarias, lamentablemente no todos los funcionarios que ocupan dichos cargos cuentan con la libertad de hacerlo ya que prima la decisión del Titular [...]”. (p.222) Efectivamente la decisión del cumplimiento de sentencias en las cuales el Estado deba pagar sumas indemnizatorias muchas veces prioriza otras actividades a cargo del Estado que pagar sus deudas sociales.

El incumplimiento del pago de sentencias judiciales por parte del Estado genera además intereses moratorios como toda deuda impaga y su efectividad y cumplimiento oportuno hace que el Estado no tenga que aportar intereses por deuda, no resultando conveniente para el ente estatal que finalmente lo conformamos todos los peruanos.

\section{Caso italiano y francés}

La experiencia italiana y francesa han demostrado una preocupación constante en regular norma especial para pagar las indemnizaciones derivadas de un daño médico en la cual el Estado como responsable deba de cumplir con el pago de sumas indemnizatorias, por ejemplo, en Francia, emitió el 4 de marzo del 2002, la Ilamada Ley Kouchner, esta ley revolucionó el sistema indemnizatorio en Francia puesto que contiene un apartado especial que regula la reparación de los daños derivados de actuaciones sanitarias, al respecto: "[...] a partir del año 2002, el derecho francés efectuó un avance, que protege tanto a los médicos como a los pacientes, mediante la mezcla de un seguro obligatorio de responsabilidad civil, y un sistema de indemnizaciones [...]" (Tamayo, 2017, párr. 1)

De lo cual se desprende que en efecto la citada ley resuelve de manera muy positiva y con acierto todos aquellos problemas de las indemnizaciones por daños causados en la prestación de servicios de salud.

El paciente que ha sufrido un perjuicio que él considera atribuible a las condiciones bajo las cuales fue tratado puede buscar la responsabilidad del hospital ante el juez administrativo. En el sistema francés se crea un procedimiento no contencioso: "[...] muy bien estructurada la Jurisdicción Administrativa, con tres niveles: Tribunal Administrativo, Corte de Apelación Administrativa y Consejo de Estado, agotándose en esta vía muchos procedimientos sobre todo de responsabilidad médica hospitalaria por sistemas de mediación y conciliación". (Hernández Moreno, Hernández Gil, \&Hernández Gil, 2002, p.11)

También es importante mencionar lo siguiente:

Cuando el daño se produce, la víctima reclamará a una comisión creada por el Estado. Dicha comisión decidirá si los daños son imputables a culpa del médico o del hospital [...] Si es lo primero, el asegurador deberá buscar la conciliación con el perjudicado, si lo segundo, será la solidaridad nacional, por medio de una entidad pública llamada la ONIAM ${ }^{1}$ la encargada de la conciliación. (Tamayo, 2017)

En España; Morón \& Ramírez (2002) en su trabajo de investigación señala que: "se ha propuesto un seguro obligatorio para los médicos que cubra los riesgos que implica el ejercicio de esta profesión, esta póliza de seguro implica un procedimiento de resarcimiento al paciente automatizado y despersonalizado". (p.213).

Como vemos los mecanismos más utilizados son los procedimientos de mediación y conciliación a fin de reclamar ante la producción de un daño médico y dicha comisión evaluará la responsabilidad del médico, del hospital o de ambos al tratarse de una responsabilidad solidaria,

Por otro lado, el sistema italiano promulgó el seguro obligatorio de las estructuras sanitarias tanto privadas como públicas, es decir, todas sin excepción, además se propugnó la incorporación de un fondo a cargo del ente estatal advierte Solano Porras (1999) con el fin de resolver el pago de las indemnizaciones y para demostrar la existencia del daño médico se crean comisiones especiales.

De tal manera ambos sistemas jurídicos regulan uno u otro mecanismo el objetivo de garantizar

1 Office National d'Indemnisation des Accidents Médicaux, des Affections latrogènes e des Infections Nosocomiales. 
indemnizaciones contra el Estado, no hacen distinciones entre hospitales privados y públicos, pero para el presente trabajo ponemos en relevancia las estructuras sanitarias públicas porque más de la mitad de la población peruana se atienden en establecimientos de salud pública así como también la normatividad vigente no permite garantizar cumplimiento del pago de indemnizaciones contra el ente estatal, radica ahí la importancia del problema. Así también existen iniciativas de la incorporación de un seguro médico en varios países de Latinoamérica como Ecuador, Chile, etc. Los cuales no son en estricto una solución al problema en cuestión, pero si constituyen una mejora en la tutela de la víctima del daño al permitir una solución extrajudicial a su reclamación indemnizatoria

Cabe mencionar el seguro obligatorio de automóviles en el ámbito internacional es tendencia actual optar y hacer de uso obligatorio de un seguro de automóviles, como es evidente la coberturas varían de un país a otro en caso de lesiones corporales tienen una cobertura ilimitada y en daños materiales se fija un momento máximo de indemnización por ejemplo en Chile el Poder Ejecutivo instauró el seguro obligatorio de Responsabilidad Civil por uno de Accidentes Personales que requería sentencia judicial previa para que la víctima recibiera la indemnización que marcaba la ley, luego reformándola se amparó solo por daños materiales en un accidente de tránsito solo para efectos de ejemplificar y posteriormente este ordenamiento no requería previa sentencia; en España la indemnización se realiza de manera inmediata si el monto no rebasa una cierta cantidad fijada por las autoridades, en caso de lo que hiciera, se tiene que probar la culpabilidad del conductor del vehículo, para poder recibir el pago correspondiente, este tipos de seguros han ido revolucionando en pro de beneficiar a los conductores de vehículos; cabe mencionar el consorcio de compensación de Seguros en España establece un fondo de garantía dentro de su ámbito territorial y hasta el límite cuantitativo del aseguramiento obligatorio de vehículos., en si son modelos que han resultado beneficiosos para garantizar una indemnización en caso de accidentes automovilísticos.

En lo que concierne a la existencia de una garantía del tipo aseguramiento obligatorio de la responsabilidad y de un fondo de garantía que asume este tipo de indemnizaciones previa sentencias condenatorias al pago de una indemnización por parte del Estado peruano en la mayoría de los casos, sin embargo, en nuestro país han presentado iniciativas legislativas frente al problema de las indemnizaciones derivados de daño médico.

Primeramente el anteproyecto presentado ante el Congreso denominado "Soat médico" (Congreso de la República del Perú, 3820/2009, Ley que crea el Seguro Obligatorio de Responsabilidad Civil Médica ) al respecto hubo muchas discrepancias unos a favor u otros en contra, por ejemplo la "Asociación Médica Peruana" se pronunció al respecto y su opinión recogida se fundamentó en un rechazo en primera instancia puesto que el seguro sería un intermediario y generaría una dilación mayor en la cual se justificaría este seguro y serian aportaciones individuales en marco al artículo. 36 de la Ley General de Salud (1997) que señala lo siguiente: "Los profesionales, técnicos y auxiliares a que se refiere este Capítulo, son responsables por los daños y perjuicios que ocasionen al paciente por el ejercicio negligente, imprudente e imperito de sus actividades" (art.36), lo cual indica un seguro profesional de los profesionales de salud de manera que se trataría de una responsabilidad individual_la que se pretendía.

Respecto al pronunciamiento de la incorporación de un Fondo de salud, quienes propugnan la creación de tal fondo es por ejemplo "La Asociación de Derechos \& Salud", desde nuestro punto de vista se trata de una responsabilidad compartida conforme al artículo 48 de la Ley General de Salud que señala: "El establecimiento de salud o servicio médico de apoyo es solidariamente responsable por los daños y perjuicios que se ocasionan al paciente [...]"

También se hace alusión a lo normado en el Título Preliminar de la Ley General de Salud considerando Cuarto que establece: "La responsabilidad en materia de salud individual es compartida por el individuo, la sociedad y el Estado." Bajo este último considerando no solamente el profesional de salud es responsable sino el Estado y se pretende aportaciones por parte de éste y se recomienda la creación de dicho fondo.

Consideramos también como otra posible solución en el ámbito de la responsabilidad civil médica, la derogación del inciso 2.1 del artículo 2 de la Ley $\mathrm{N}^{\circ}$ 30137, Ley que regula criterios de priorización para la atención de pagos contra el Estado peruano, la cual genera menores ventajas a las sentencias derivadas de daños médicos en instituciones de salud públicas, previa derogación de la misma y que el ente estatal establezca mecanismos legales recomendados por el Tribunal Constitucional así como el presupuesto 
Gráfica 1. Alternativas de solución al problema

ENCUESTA 2017:

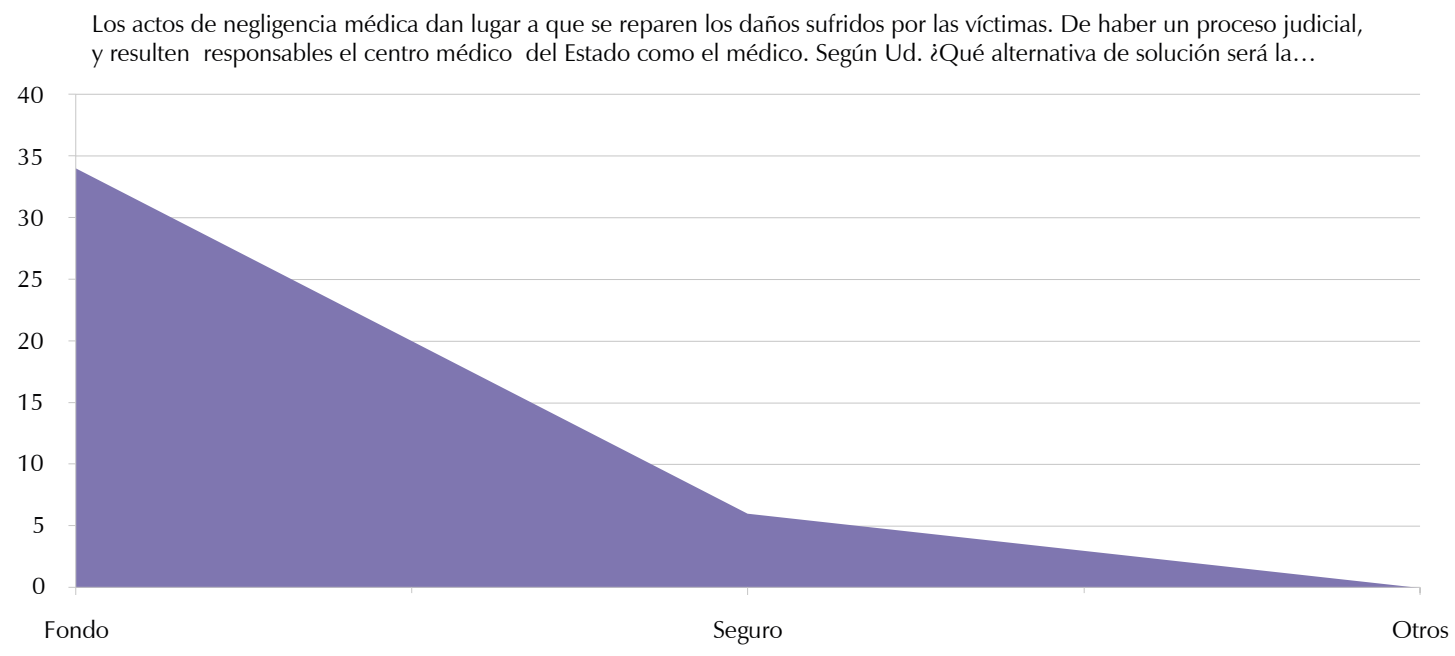

Fuente: Elaboración propia a partir de los datos de la encuesta.

de la República sea adecuadamente asignado de tal manera que anualmente el Ministerio de Economía y Finanzas abra partidas presupuestarias para el pago de deudas sociales y que se cumpla con las modificaciones y previsiones presupuestarias que la Ley $\mathrm{N}^{\circ} 27584$ regula.

En definitiva, se puede observar que la sociedad peruana reclama con urgencia una verdadera tutela del derecho a la salud, la investigación realizada se recolectó datos estadísticos de ambas iniciativas legislativas propuestas por diferentes sectores a fin de resolver el pago de las indemnizaciones en el sector salud.

\section{Encuesta 2017²: Opiniones Recogidas}

Para estudiar la importancia del problema planteado en la investigación y encontrar alternativas de solución resultó necesario realizar una encuesta de opinión dirigida a la población médica de la ciudad

2 Se aplicó a 40 médicos en el ejercicio de su profesión y que trabajen en estructuras sanitarias públicas en el año 2017 en la ciudad de Arequipa, se recogió dicha muestra a través del instrumento, siendo este un cuestionario de forma presencial elaborados en base a cuatro preguntas sencillas y fáciles de comprender, de opción múltiple, se contrató a una persona adicional a la investigadora para lograr recabar la información, los datos personales de los médicos no fueron requeridos, fueron anónimos, se recorrió hospitales públicos, el seguro social de salud, postas médicas, etc. Para el presente artículo se extrajó las principales preguntas relevantes para el problema. de Arequipa, en estructuras sanitarias públicas, tomándose una muestra de 40 profesionales de la salud, las encuestas fueron formuladas de manera homogénea Las encuestas se realizaron a través de un instrumento para la recolección de información, diseñada para cuantificarla, elaboradas en base a cuatro preguntas sencillas y fáciles de comprender, de opción múltiple, en el presente artículo se consideró solo las más relevantes, se contrató a una persona adicional a la investigadora para lograr recabar la información, los datos personales de los médicos no fueron requeridos, fueron anónimos, se recorrió hospitales públicos, el seguro social de salud, postas médicas, etc. Se realizó dicha encuesta para buscar alternativas de solución al problema que se trata en el presente artículo.

Para verificar la validez del cuestionario, se realizó una prueba piloto, con diez preguntas iniciales que fueron descartándose y reduciéndose a tres en base a puntuaciones, en la prueba piloto se solicitó que escogieran tres preguntas a un grupo de 10 médicos. Así también se corrobora que existe correlación entre las variables a través de un análisis multivariado elaborado en Stata 2013 (Gráfico 3), La prueba de Kaiser-Meyer-Olkin (KMO) estima un valor que de acuerdo a su ubicación en una escala permitir concluir si del análisis realizado es conveniente, ya que obtuvimos un $\mathbf{0 . 5 1 7 9}$, siendo un valor que no es inferior a $\mathbf{0 . 5}$, puesto que, si este valor KMO se aleja, es más conveniente, se rechaza la hipótesis nula HO. 
Por tanto, se concluye que es poco probable que la matriz de correlación sea una matriz de identidad, y por tanto la correlación entre las variables es estadísticamente significativa.

Interpretación: El 85\% de médicos encuestados aceptan como posible solución el Fondo Médico, mientras que el 15\% aceptan el Seguro Médico, el resto en $0 \%$.

\section{Gráfica 2. Viabilidad de aportes a un Fondo ENCUESTA 2017}

Si respondió LA ANTERIOR A. ¿Estaría Ud. de acuerdo que su remuneración mensual sea afectada entre el $0.5 \%$ al $1 \%$, a fin de que dicho monto se destine a un fondo para el pago de indemnizaciones en caso del daño médico en el sector público?

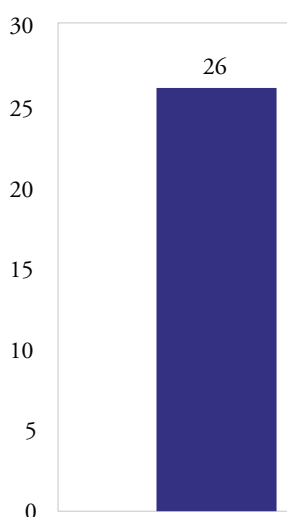

SI

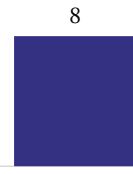

NO
Fuente: Elaboración propia a partir de los datos de la encuesta.
Interpretación: El 26\% de médicos encuestados aceptan la posibilidad de afectar su remuneración mensual en un 1 al 5\% con el fin de destinarlo al Fondo, sin embargo, solamente el $8 \%$ no estarían dispuestos.

Interpretación: El 97.50\% de médicos encuestados consideran al presupuesto como causa, mientras que solamente el $2.5 \%$ no la consideran. Solamente el $37.50 \%$ consideran como causa, a los funcionarios públicos mientras que el $62.50 \%$ no la consideran. El $77.50 \%$ de médicos encuestados consideran a la legislación normativa como causa, mientras que solamente el $22.50 \%$ no la consideran. Solamente el $32.50 \%$ como causa consideran a la cultura estatal de no pago, mientras que el $67.50 \%$ no la consideran.

En primer lugar, se realizó esta encuesta de opinión precisamente para conocer la opinión del profesional de salud, referente a las causas que ocasionarían el incumplimiento a las sentencias (Grafica $N^{\circ} 3$ ), los resultados obtenidos fueron: el presupuesto como las normas legales, lo cual corrobora el análisis normativo estudiado, en cuanto al presupuesto es una causa que está a cargo del gobierno peruano en coordinación con el Ministerio de Economía y Finanzas.

En segundo lugar, a raíz de las sugerencias y anteproyectos de ley presentados ante el Congreso de la República y al no haber una sólida aceptación de uno u otro mecanismo de solución. Se obtuvó como

Gráfica 3. Principales causas que ocasionan demora en el cumplimiento de pago ENCUESTA 2017:

¿Cuál o cuáles causas según Ud. considera que ocasionan demora en el cumplimiento de pago por parte del Estado a los pacientes?

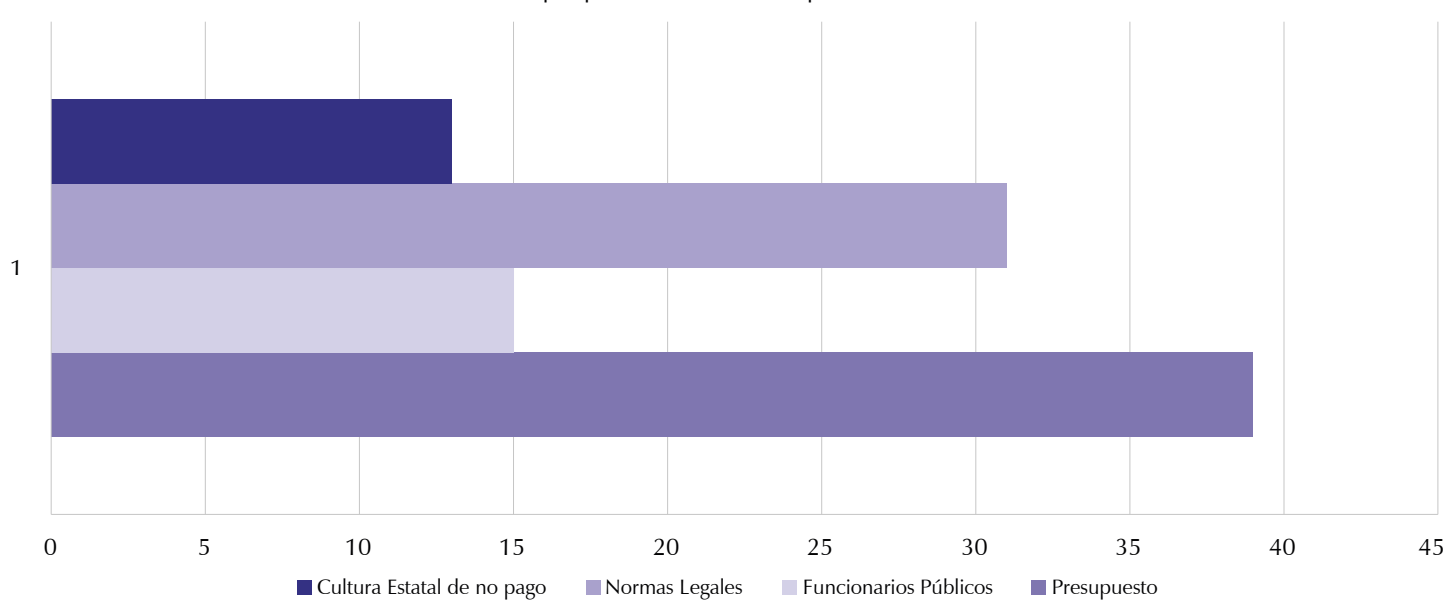

Fuente: Elaboración propia a partir de los datos de la encuesta. 
resultados de las encuestas de opinión que ambas posibles soluciones tanto el Fondo como el Seguro son medidas que los profesionales médicos en la ciudad de Arequipa serían aceptados y en menor cuantía la disposición de aportar económicamente, sin embargo, no se descarta ese aporte como se observa en las encuestas.

Los resultados obtenidos fueron que ante posibles alternativas de solución frente al problema se optaría por un Fondo de Salud y si fuese viable esta opción los encuestados señalaron que estarían dispuesto a aportar entre el 0.5 al 1\% de su remuneración. Por otro lado, se considera de gran importancia la Grafica 3, por ser significativa siendo el eje del principal objetivo de la investigación los galenos consideraron como causas principales que ocasionan el incumplimiento por parte del Estado peruano tanto al presupuesto como la legislación normativa obtuvieron los porcentajes más altos, lo que contrasta nuestra hipótesis principal.

Al respecto sí se optaría por un fondo o seguro de salud cabe mencionar a Maylle (2012) menciona a la ASOCIACIÓN MÉDICA PERUANA la cual se pronunció sobre la creación de un seguro médico obligatorio, para la asociación esta propuesta no generaría ningún beneficio, sino todo lo contrario ocasionaría perjuicios a toda la población peruana, porque acarrearía doble proceso judicial por un lado para el cobro de la indemnización y por el otro lado juicio contra la aseguradora y esta solución no sería para nada el remedio.

No se considera una negativa total en esta investigación porque en países extranjeros el seguro ha funcionado muy bien beneficiando a los pacientes y en futuro lejano se recomendaría mejorar las propuestas legislativas peruanas que han sido archivadas, denegadas, y que sean nuevamente evaluadas por parte del comité evaluador.

Según Maylle (2012) comenta que en cuanto a la creación de un fondo, LA ASOCIACION SALUD\& DERECHOS menciona que se debería de construir a partir de aportes de todos los trabajadores y de las instituciones de salud, el monto es otro punto en debate, dicho fondo se podría cubrir satisfactoriamente conforme la ley puede generar un aporte inmediato que indemnice satisfactoriamente un caso de la mala práctica médica con tres millones seiscientos mil nuevos soles y se construiría con un sol , sin intermediarios, se podría sostener dicho fondo.
Se puede recomendar que ante la creación de un fondo de salud, se generaría un monto correspondiente al pago de deudas sociales por daño médico y sería destinado al pago por responsabilidad civil sanitaria al inicio de cada año fiscal de cumplimiento obligatorio, en caso de incumplimiento se sugiere que la Superintendencia Nacional de Salud (SUSALUD) en coordinación con el órgano jurisdiccional deberán de tomar las medidas coercitivas necesarias y de ser el caso procesar al desobediente, suspendiendo sus funciones.

También el Ministerio de Economía y Finanzas debería calcular el porcentaje de asignación presupuestal que le corresponda al pliego por la fuente de recursos ordinarios establecido en el inciso 47.3 de la Ley $N^{\circ} 27584$, Ley que Regula el Proceso Contencioso Administrativo deduciendo el valor correspondiente a la asignación para el pago del servicio de la deuda pública derivado de daño médico, Se considera que este fondo sería viable.

\section{CONCLUSIONES}

Las principales causas normativas que ocasionan el incumplimiento de sentencias por responsabilidad civil derivado de un daño médico en estructuras sanitarias del sector público evidencian lo complicado y engorroso que es ejecutar una sentencia en el Perú y los menos favorecidos son los pacientes, por ello el Tribunal Constitucional se ha pronunciado en el sentido de no otorgar privilegios al Estado peruano, de lo contrario sería ir contra el principio constitucional de igualdad ante la ley, sin embargo, la actual normativa existente no garantiza el cumplimiento de sentencias judiciales.

En la actualidad la norma para ejecutar sentencias judiciales contra el Estado se encuentra regulado por el artículo 47 de la Ley $N^{\circ} 27584$, Ley que regula el Procedimiento Contencioso Administrativo, la cual ha sido complementada con el artículo 70 de la Ley 28411, Ley General del Sistema Nacional del Presupuesto, dicha normativa es una causa dilatoria la cual no brinda las garantías necesarias y debidas para que los titulares de un derecho puedan cobrar sus deudas sociales.

La Ley $N^{\circ} 30137$, Ley que establece criterios de priorización para la atención del pago de sentencias judiciales contra el Estado, dicha norma es una causa dilatoria que prioriza el pago de unas sentencias de otras, regulando a las sentencias por daño médico 
en una penúltima posición, lo cual atenta contra el derecho a la igualdad como la tutela jurisdiccional efectiva, lo cual no permite que se efectivice las indemnizaciones derivadas de un daño médico en establecimientos de salud pública.

La Constitución Política del Perú como las normas del Código Procesal Civil regulan la inembargabilidad de los bienes del Estado, siendo una causa normativa que impide el cumplimiento de las sentencias judiciales contra el Estado el cual por un lado busca evitar poner en riesgo el funcionamiento mismo del Estado, pero por otro lado no se puede invocar cuando se trate de mandatos judiciales con el fin de garantizar la seguridad jurídica y el respecto de los derechos reconocidos a las personas en dichas sentencias.

Los bienes del Estado son de dominio público y privado, son embargables los bienes de dominio privado, existiendo un vacío legal que fije qué bienes son susceptibles de trabar embargo y al no haber un listado en estricto, el Tribunal Constitucional ha designado realizar la distinción bien público de privado al órgano jurisdiccional, sin embargo, en la práctica ha resultado difícil tal distinción siendo las solicitudes de los demandantes declarados improcedentes.

La legislación comparada nos enseña el interés de los Estados por garantizar el cumplimiento del pago de las indemnizaciones a favor de los pacientes, emitiendo normativa propia que evita seguir el procedimiento contencioso administrativo, lo cual reduce tiempo, dinero lográndose un cumplimiento oportuno y pronto de las indemnizaciones.

La falta de mecanismos legales no permite garantizar el cumplimiento de las sentencias judiciales honrando el pago de las deudas sociales por daño médico y otras sentencias de diversa materia lo cual constituye una deficiencia de nuestra actual legislación.

\section{RECOMENDACIONES}

\section{Recomendaciones específicas}

La derogación del inciso 2.1 del artículo 2 de la ley N³0137, Ley que prioriza el pago de las sentencias judiciales por materia, con la finalidad que todas las sentencias incluyendo aquellos mandatos derivados de daños médicos se encuentren en las mismas condiciones, sin priorización por materia y no afecte derechos constitucionales como la igualdad y tutela jurisdiccional efectiva y éste último comprende el derecho a la ejecución de sentencias judiciales.

Se recomienda también desarrollar normativa para ejecutar las sentencias judiciales por daño médico, mediante el cual se establezca un fondo por responsabilidad del profesional de salud que pretenda honrar la deuda social de aquellos pacientes donde el profesional de la salud apoye con aportaciones simbólicas y no sea el Estado el único en soportar el pago la deuda social, sin intermediarios.

Sin perjuicio de la anterior recomendación, en muchos países de latinoamericana y el mundo adoptan un sistema de indemnizaciones a través de los seguros de responsabilidad civil médica y funciona muy bien que deban de contratar las instituciones de salud públicas, lo cual se debería replantear en un futuro próximo a efectos de resolver el problema indemnizatorio, sin dejar de lado la función preventiva de la responsabilidad civil es decir, fortalecer los esquemas preventivos que reduzcan o eviten daños ocasionados en el ejercicio profesional médico, solo así estaremos brindando una verdadera tutela al derecho de la salud.

Se recomienda que se establezcan lineamientos que determinen y fijen qué bienes pueden ser susceptibles de embargo, no obstante, el Tribunal Constitucional lo sugiere para una mejora en la tutela jurisdiccional efectiva.

\section{Recomendación general}

Previa derogación (La derogación del inciso 2.1 del artículo 2 de la ley $N^{\circ}$ 30137) que el Estado peruano desarrolle normativa para la ejecución de sentencias, contando con mecanismos legales que garanticen el cumplimiento de las sentencias judiciales abriéndose una etapa de supervisión como lo realiza la Corte Interamericana. 


\section{REFERENCIAS}

Bustamante R \& Flores G. (2004), El daño objetivo derivado de la responsabilidad civil médica como elemento indispensable en la presunción de la culpa, Lima, Perú.

Carhuatocto H. (2010). La Responsabilidad civil médica: El caso de las infecciones intrahospitalarias, Tesis de Magister. Universidad Nacional Mayor De San Marcos Lima, Perú recuperado de: http://cybertesis.unmsm.edu.pe/bitstream/ handle/cybertesis/198/Carhuatocto_sh(1).pd f; jsessionid=800B3C56184096AFCFA1C031 $54 \mathrm{C} 04 \mathrm{E} 2 \mathrm{~A}$ ? sequence $=1$.

Carta Europea de los Derechos de los Pacientes. Segunda Parte: Catorce Derechos Del Paciente. 2002, Roma: Italia, recuperado de http://cecu. es/campanas/sanidad/European_Charter_of_ Patients_Rights_in_Spanish\%5B1\%5D.pdf.

Canales C. (2007) Un supuesto de triple responsabilidad civil; A propósito de los daños producidos como consecuencia de transfusiones de sangre en instituciones públicas. Lima, Perú: Editorial: Gaceta Jurídica. Dialogo con la Jurisprudencia $N^{\circ} 109$.

Casassa S. (2016), El debido proceso de ejecución de obligación de dar suma de dinero, Lima, Perú: Editorial: Instituto Pacifico S.A.C.

Código Civil [CC]. (1984). Decreto Legislativo N² 295, de fecha 14 de noviembre de 1984, Perú.

Código Penal [CP]. (1984). Decreto Legislativo № 635 , de fecha 08 de abril de 1991, Perú.

Código Procesal Civil [CPC]. (1993). Decreto Legislativo №768, de fecha 4 de marzo de 1992, Perú.

Código Civil Español, Real Decreto de 24 de julio de 1889

Colegio de Abogados de Ica, Defensoría del Pueblo (Acumulados). Resolución judicial [acción de inconstitucional], Exp. N. o 015-2001-AI/TC Exp. N. ㅇ 016-2001-Al/TC Exp. N. o 004-2002$\mathrm{Al} / \mathrm{TC}$, sentencia (Tribunal Constitucional [Perú], 29 de enero del 2004).

Sociedad de Comercio Exterior del Perú - ComexPerú (2019), Estos son los desafíos en salud pública en Perú, Perú: Confiep( La Confederación Nacional de Instituciones Empresariales Privadas) Empresarios haciendo país, recuperado de: https://www.confiep.org.pe/noticias/ destacado/estos-son-los-desafios-en-saludpublica-en-peru/

Congreso de la República (2013). Dictamen recaído en el Proyecto de Ley 1478/2012-CR por el cual se propone la Ley que establece el seguro obligatorio de responsabilidad médica, e incorpora el delito de negligencia médica. Recuperado de: http://www2.congreso.gob. pe/Sicr/ApoyComisiones/comision2011.nsf/ DictamenesFuturo/ED3EC9E11FBACDFA05 257B6E005ED3C4/\$FILE/SALUD.POB_14782012-CR_Archivo.Mayor\%C3\%ADa.pdf.

Congreso de la República (2015). Proyecto de dictamen de no aprobación recaído en el Proyecto de Ley 2713/2013- CR, que propone la Ley que crea el Fondo de Riesgo del Ejercicio Profesional de la Medicina. Recuperado de: http://www2.congreso.gob.pe/sicr/comisiones/2014/com2014salud.nsf/0/72c862bffaf 3751005257e4a006ee080/\$FILE/Proy_de_ dict_PL_2713_Fondo_de_Riesgo.pdf.

Constitución Política del Perú, de fecha 29 de diciembre de 1993, Perú.

Costa F. (2018), Población afiliada a algún seguro de salud, Lima: Perú, recuperado de: https:// www.inei.gob.pe/media/MenuRecursivo/publicaciones_digitales/Est/Lib1587/libro01.pdf

Defensoría del Pueblo (1998), Incumplimiento de las sentencias por parte de la administración estatal. Lima: Perú. Recuperado de: https://www.defensoria.gob.pe/wp-content/ uploads/2018/05/informe_19.pdf

Encuesta (2017). Finalidad: Establecer alternativas de solución al problema planteado. Dicha encuesta ha sido financiada por fondos concursables CIENCIACTIVA-UNSA, Arequipa: Perú.

Espinoza J. (2006), Derecho de la Responsabilidad Civil: Lima, Perú, Editorial: Gaceta Jurídica. Cuarta Edición.

Espinoza J. (2014), La Reparación civil derivada de los delitos de corrupción en agravio del Estado: ¿qué derecho no patrimonial se lesiona? Parte 1, Perú: IUS ET VERITAS, recuperado de: https://ius360.com/jornadas/ jornada-por-los-30-anos-del-codigo-civil/ 
la-reparacion-civil-derivada-de-los-delitosde-corrupcion-en-agravio-del-estado-quederecho-patrimonial-se-lesiona-parte-1/\# $\mathrm{ftn} 14$

Espinoza J. (2016), Derecho de la Responsabilidad Civil: Lima, Perú: Editorial: Instituto Pacifico S.A.C., Octava Edición-septiembre 2016.

Estrella Y. (2009), El Nexo causal en los procesos por responsabilidad civil extracontractual, Tesis de Magister. Universidad Nacional Mayor De San Marcos Lima, Perú recuperado de: http:// cybertesis.unmsm.edu.pe/bitstream/handle/ cybertesis/205/Estrella_cy.pdf;jsessionid $=6$ 8B89C6BEA2C09A7BB4DF85529D47A80? sequence $=1$

Expediente $\mathrm{N}^{\circ}$ 01664-2007-0-0401-JR-Cl-07, de fecha 25 de abril del 2006, Perú.

García V. (2014), Teoría del Estado y Derecho Constitucional: Lima, Perú: Adrus D\&L Editores S.A.C.

Hernández Moreno, J., Hernández Gil, M. L., \& Hernández Gil, A. (2002). Responsabilidad por malpraxis médica: la vía extrajudicial. Cuadernos de Medicina Forense, 07-24.

Instituto Nacional de Estadística e Informática (2013), Estadísticas: Salud, Perú, recuperado de: https://www.inei.gob.pe/estadisticas/indicetematico/health/

Ledesma M. (2013), Las medidas cautelares en el proceso civil, Lima: Perú: Editorial: Gaceta Jurídica S.A.C.

Ley №30137, 2014, Reglamento De La Ley № 30137, Ley Que Establece Criterios De Priorización Para La Atención Del Pago De Sentencias Judiciales. DO 516938. El peruano.

Ley General de Salud, Ley № 26842, de fecha 15 de julio de 1997, Perú.

Ley $N^{\circ} 28411$, Ley General del Sistema Nacional de Presupuesto, de fecha 6 de enero del 2005, Perú.

Ley $\mathrm{N}^{\circ} 27584$, Ley que regula el Procedimiento Contencioso Administrativo, de fecha 6 de diciembre del 2001, Perú.

Ley $N^{\circ}$ 303, "ley Kouchner", 4 de marzo de 2002, Francia.

Leysser L. (2017), La responsabilidad civil: Líneas fundamentales y nuevas perspectivas, Lima,
Perú: Editorial: Instituto Pacifico S.A.C, Tercera Edición.

Luis Alberto Lalupu Sernaqué c. Resolución judicial [acción de amparo], expediente 02598-2010PA/TC, sentencia (Tribunal Constitucional [Perú], 11 de junio de 2013).

Maylle L. (2012), Tratado de Negligencia Médica, Lima, Perú: Edición 2012.

Morón M \& Ramírez M. Contrato de Seguro de Responsabilidad Civil Médica Tesis Pontífice Universidad Javeriana, Bogotá, Colombia, recuperado de: https://www.javeriana.edu. co/biblos/tesis/derecho/dere4/Tesis-42.pdf

Pérez J. (2014). Plazo y eficacia de las sentencias judiciales. "Delimitando un nuevo camino para la satisfacción del interés". En Ponencias del Cuarto Seminario Internacional del Derecho Procesal: Proceso y Constitución, Lima: Perú: Editorial: Palestra Editores S.A.C.

Pisconte L. (2015), Comentarios a la Ley del Proceso Contencioso Administrativo, Lima, Perú: Editorial: San Marcos de Aníbal Paredes Galván.

Priori G. (2007). Comentarios a la Ley del Proceso Contencioso Administrativo, Lima, Perú: Editorial: ARA Editores E.I.R.L.

Sánchez L. (2015) La Responsabilidad Patrimonial de la Administración Pública en el Ordenamiento peruano: Aproximaciones a una Institución pendiente de Reforma, 325.

Sentencia del Tribunal Constitucional, Expediente Nº06-96-I/TC, 30/01/1997, Lima, Perú.

Solano Porras, J. (1999). El seguro contra la responsabilidad civil del médico. Medicina Legal de Costa Rica, 16, 21-27.

Tamayo, J. (2018). Responsabilidad médica en Francia. El sistema ideal. Recuperado de: https://www.ambitojuridico.com/noticias/ columnista-impreso/civil-y-familia/responsabilidad-medica-en-francia-el-sistema-ideal

Villa-García M. (2014). La cultura estatal del no pago, el caso de los bonos de la reforma agraria, y la inexplicable intervención del Tribunal Constitucional 12 años después de haber expedido sentencia. En Ponencias del Cuarto Seminario Internacional del Derecho Procesal: Proceso y Constitución, Lima: Perú: Editorial: Palestra Editores S.A.C. 


\section{ANEXOS}

Anexo 1. Modelo de encuesta aplicada.

ENCUESTA REALIZADA A MÉDICOS DE LA CIUDAD DE AREQUIPA.

Se solicita su autorización para participar en el proyecto de investigación titulado: "Incumplimiento de las sentencias por Responsabilidad Civil derivado del Daño Médico que ordenan al Estado peruano un pago indemnizatorio". Cuyo objetivo es conocer la opinión del profesional médico en torno al problema social que se estudia.

El objetivo que se esperan de este trabajo es beneficiar al paciente-victima a quien se le adeuda el pago de una indemnización por parte del Estado peruano, con este estudio se pretende buscar alternativas de solución en favor de los demandantes.

La participación en éste estudio es totalmente voluntaria, la respuesta es completamente anónima, por lo que no se solicitará ningún dato que pueda identificarle, conforme a la Ley peruana $\mathrm{N}^{\circ}$ 29733, ley de Protección de datos personales, Si tienen alguna pregunta sobre este proyecto de investigación puede consultar en cualquier momento a la Investigadora Betty Alca Gómez, cuyo e-mail es:balcagomez@gmail.com.

Si usted responde a las cuestiones que se le proponen, se entiende de forma tácita que ha brindado su consentimiento para el presente estudio y que acepta participar. La investigadora le agradece su valiosa participación en el presente estudio.

\section{PREGUNTAS:}

1. Existe alguna institución alguna institución donde labora actualmente un órgano de control y supervisión en la cual el Estado cumpla con pagar a las víctimas por negligencia médica previamente judicializada?
a. SI
b. NO

2. Los actos de negligencia médica dan lugar a que se reparen los daños sufridos por las víctimas. De haber un proceso judicial y resulten responsables el centro médico del Estado como el médico. Según Ud. ¿Qué alternativa de solución sería la idónea?
a. Fondo
b. Seguro
c. Otros

3. Si respondió la anterior A. Estaría Ud. de acuerdo que su remuneración mensual sea afectada entre el $0.5 \%$ y $1 \%$, a fin de que dicho monto se destine a un fondo para el pago de indemnizaciones en caso del daño médico en el sector público?
a. SI
b. NO

4. ¿Cuál o cuáles causas según Ud. Considera que ocasionan demora en el cumplimiento de pago por parte del Estado a los pacientes?
a. Cultura Estatal de No pago
b. Normas Legales
C. Funcionarios Públicos
d. Presupuesto. 